\title{
An Effective Absenteeism Policy: How Employers Use it to Improve Employees' Attendance Behavior, Working Life?
}

\section{Mohammed Aldoghan \\ mdoghan@kfu.edu.sa}

\author{
Musaddag Elrayah \\ melrayah@kfu.edu.sa
}

\author{
Management Department \\ School of Business \\ King Faisal University \\ Eastern Area, Hassa, Hofuf, KSA
}

\begin{abstract}
The traditional viewpoint always looks to employees as a source of the problem. Examining the relationship between an effective absenteeism policy and employees' attendance behavior as well as their wellbeing at work will change this viewpoint. 219 employees from the petrochemical sector in the Eastern Area targeted for this study. A sample of 139 employees selected randomly for the purpose of this study. 22 questions are formulated to study the main indicators of the relationships between the variables of this study. A self-administered questionnaire used a five-point Likert structured sent through emails to 139 respondents who represent the selected sample of employees from the eastern area industrial sector. Data collected was analyzed to provide some descriptive and correlations results. Study findings have shown a positive correlation between the variables of this study. The findings show that an effective absenteeism policy might help to decrease the work-related accidents, decrease the work-related illness, improving the overall attendance satisfaction and employees' wellbeing.
\end{abstract}

Keywords: An Effective Absenteeism Policy, Employees Attendance Behaviour, Working life.

\section{Introduction}

The issue of absenteeism and its effect on business performance generally and employee life specifically studied and discussed by different authors many years ago. The earlier studies in this area focused on the factors that lead to high rate of absenteeism like the effects of personnel characteristics on absence rate and how these characteristics related to job satisfaction (Furnham \& Bramwell, 2006). The majority of these researches focused on the impact of absenteeism on productivity, employees' attitudes and tried to measure absenteeism costs (Steers \& Rhodes, 1978), some of these studies focus on environmental factors that affect absenteeism and the role played by organizations to overcome these factors (Athanasou \& Murphy, 1981). Recent studies also try to explore the main reasons that lead to increase the rate of absenteeism in organizations and how this rate affect the organizational performance (Duncombe, 2019). Some of these studies differentiate between absenteeism levels in different types of employee's according to theirs contract. Their findings show that permanent contract employees are expected to be absent more than the temporary employees (García Mainar, Green \& Navarro Paniagua, 2018).

\footnotetext{
* This article was submitted in December 2019, accepted for publishing in March 2020 and published on March 2021.

(c) Arab Administrative Development Organization- League of Arab States, 2021, pp 381-389، DOI: 10.21608/aja.2021.188911
} 
The role of human resource management interventions is vital in managing and controlling of absenteeism rate as well as increasing the employees' satisfaction by formulating and implementing an effective absenteeism policy that helps employees to benefit from being absent and minimize the side effects of absenteeism on the organization performance at the same time (Strömberg, Aboagye, Hagberg, Bergström \& Lohela-Karlsson, 2017). The creation of this balance might lead to satisfy all parties, employees as well as organizations. Some recent studies try to find strategies and solutions to reduce the absenteeism rate in organizations (D'Agostino et al., 2018). A survey conducted by the Society of Human Resource Management (SHRM) revealed that employee absences affect organization's productivity as well as revenue. This study reflected the negative consequences of absenteeism. The majority of studies in this area focused their results on the negative consequences and implications of absenteeism. Very few studies have shown the positive consequences of absenteeism on employee health \& safety, wellbeing, professional life, and work-life balance.

Chartered Institute of Personnel Development (CIPD) mentioned that by creating and sustaining a conducive working environment and by promoting wellbeing, organizations could create a positive working environment where individuals and organizations can both benefits. An effective and useful attendance management help employee to be more productive (CIPD, 2019). The working environment is changing rapidly providing new constraints for managing people at work. In addition, the economic environmental factors in which firms operate can affect the working environment as well as having effect on employees' behavior and their absenteeism records (Mowday, Porter \& Steers, 2013). Studies show that employees support facilities at work might help to reduce their absenteeism as well as their family's conflicts (Goff, Mount \& Jamison, 1990). Today, managers are not concerning by what make employee absent, but they also try to find the factors that delight them and make them happy and productive. Human resource management in most of international organizations realize the importance of an effective absenteeism policy in the workplace. Three -fifth to twothirds of organizations have formal written attendance policy (SHRM,2014).

In this study, we try to explore how effective human resource management using an effective absenteeism policy can minimize the level of absenteeism as well as improving employees' satisfaction, their wellbeing, work-life balance, work-related stress, work-related illness, work-related accidents and their professional development. As stated by CIPD report, an effective management policy might help to promote engagement and attendance as well as keep sickness absence at the lower level.

\section{Litrature Review}

Organizations today try to do their best and continually innovate methods and policies that help their people satisfy and productive. The job of policy formulation always assigned to Human Resource Management (HRM) as well as the strategists in these organizations. Policies formulated to meet the needs of strategic issues and aligned with the organization's strategy. An effective absenteeism policy is a written policy that states clearly the attendance expectations in a specific organization. It should clearly guide, direct and motivate employees to perform their jobs and enjoy their working conditions. The accountability of implementation for this policy is the job of the front-line managers as well as HRM.

Organizations should proactively manage their absenteeism as well as presenteeism to improve their overall performance and attain their strategic goals. By high commitment to absenteeism issue, we can expect that organizations approved an accepted amount of budget for managing and running their employees' attendance records through an effective absenteeism policy. (Baker-McClearn, Greasley, Dale \& Griffith, 2010) found a positive correlation between the way through which organizations manage their absenteeism and their employees' well-being and performance. These results show that an effective management of attendance might help employees to have a high level of job satisfaction that leads to high organizational performance. It also helps organizations to realize the negative side of presenteeism and providing their employees 
a chance to have some time a way of their jobs without any operational deficiencies. (Hemp, 2004). Some organizations which have no effective absenteeism policy face what defined as presenteeism where employees come to their jobs even if they are facing illness or injured and add some risks to the work environment which supposed to be healthy and safe (Dew, Keefe \& Small, 2005). The issue of managerial problems related to absenteeism studied widely by many researchers. (Edwards \& Scullion, 1984) have tried to find some practical methods to solve the managerial consequences related to this phenomenon, but they ignore the benefits side of the absenteeism to employers and employees if managed effectively.

Absenteeism might also lead to decrease the costs related to work injuries. Study done by (Lu, Nakata, Park \& Swanson, 2014) suggest that organizations to study and comprehend the factors that link between the organization's work factors and injury absence one to make an operational plan that help to reduce these costs. The study tries to connect between the injury absence rate in organizations and the policy of work as well as absence management. If organizations use an effective absenteeism policy this might help employees to ignore presenteeism and take a short leave when they feel ill, therefore, they might protect themselves and others from injury absences in the future. An ineffective absenteeism policy might increase the level of work-related stress that lead to high costs.

Study by (Fang, Lee, Timming \& Fan, 2019) found positive relationships between the well-being programs and the management outcomes like reducing costs, improving the absenteeism rate, increasing employee morale and satisfaction as well as higher retention rate. The study also mentioned the impact of flexible working schedules that help organizations to improve the outcomes. If organizations pay more attention on their well-being programs, these might lead to increase their workers job satisfaction and improve their attendance behavior by reducing the absenteeism rate. Other study by (Matilla-Santander et al., 2019) found an association between work-life balance and organization's working hours. This study also reveals the strong relationship between the management policy generally and absenteeism policy in specifically which allow employees to have time absence and increase the satisfaction level as well as reducing the absenteeism rate. Many employees have been absent of their jobs because of family excuses and the lack of an effective absenteeism policy. The absenteeism policy which permits employees to quit for their personnel reasons or sick leave reasons might improve the employee satisfaction as well as commitment toward organization. (Kim \& Ryu, 2017) found a positive relationship between the compensatory time-off and paid-sick and employee commitment. From their finding we can link between the effective management policies generally and the absenteeism policy in specifically and the employee's commitment as well as productivity.

Another important factor that should be discussed here the work-related illness. There are many factors affect the level of work-related illness. Majority of these factors are management practices and polices related factors. Organizations should pay more attention on the factors that prevent employees from work-related illness. The well-formulated absenteeism policy might lead to decrease the rate of work-illness rate in organizations. There are some recommended interventions by management which help to reduce the work-related illness and work-related accidents like reduce hazards, modifying of the routine tasks and improving the working control.

From the given literature, following research model showing the positive and negative relationships between independent variable and dependent variables designed. In addition, the main hypotheses of the study have formulated.

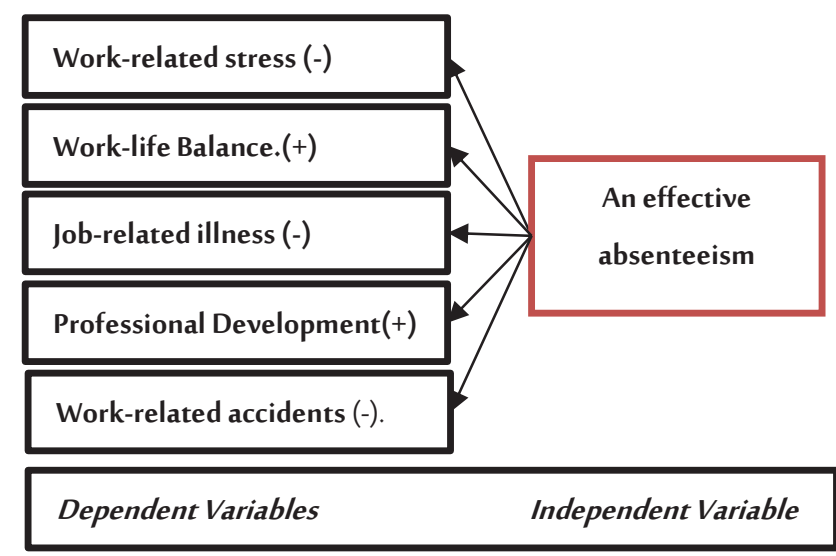

Figure 1: Study Model Framework 


\section{Hypothesis of the Study}

The main hypotheses of this study are:

- H1: An effective absenteeism policy help employees to be satisfy on their attendance behavior.

- H2: An effective absenteeism policy reduces the work-related stress for employees.

- H3: An effective absenteeism policy improves the work-life balance for employees.

- H4: An effective absenteeism policy reduces possibility of job-related illness for employees.

- H5: An effective absenteeism policy helps employee to develop professionally.

- H6: An effective absenteeism policy decreases the rate of work-related accidents.

\section{Methodology}

\section{Methods:}

The total population of about 219 Saudi's employees from eastern area industrial sector, including male and female who enrolled in MBA program in school of business, King Faisal University in the years 2015/2019. A sample of 139 employees selected randomly for the purpose of this study. The researchers apply Stephen K. Thompson, 2012, Third edition, p: 59-60 to calculate the sample of this study.

\section{Measures:}

About 22 questions constructed and used as the main indicators of the variables of this study. Some items tested by CIPD (2018) in their absence annual survey used to measure employee satisfaction toward absenteeism policy as well as their attitude toward dependent variables items. Using employees' emails, a self- administered questionnaire with a five-point Likert structured has sent to all selected sample. Five of the main questions designed to aske respondents to rate on a five-scale rating about the main reasons for absenteeism. The remaining questions construct to measure respondents attitudes about the positive effects of an effective absenteeism policy.

\section{Analysis:}

Data collected and analyzed using a descriptive statistic that aligned with the type of this study. Pearson's Correlation coefficient also used to test the significance as well as the correlation between variables used in this paper. Analysis of the data done by SPSS.

\section{Findings \& Discussion}

Table (1) shows the means and standard deviations for the factors that lead to absenteeism according to employees' viewpoints .It shows that employees might be absent of their jobs because of their unwillingness to their current jobs as main factor, long distance between work location and their homes, routine job activities, family reasons and medical reasons respectively.

Results in table (2) show the descriptive statistics in terms of arithmetic mean and standard deviation regarding employees' attitudes for the positive side of an effective absenteeism policy. The table shows that an effective absenteeism policy might help employees who replace the absent employee and playing their
Table (1): Descriptive Statistics: Mean and Std. for the Reasons of Absenteeism

\begin{tabular}{lccccc}
\hline & N & Minimum Maximum & Mean & $\begin{array}{c}\text { Std. } \\
\text { Deviation }\end{array}$ \\
\hline Family reasons & 139 & 1.00 & 5.00 & 2.7266 & 1.50750 \\
\hline Routine job activities and exhausted & 139 & 1.00 & 5.00 & 2.7914 & 1.58102 \\
\hline Unwillingness in my current job & 139 & 1.00 & 5.00 & 3.9424 & 1.35545 \\
\hline $\begin{array}{l}\text { Long distance between work lo- } \\
\text { cation and my home }\end{array}$ & 139 & 1.00 & 5.00 & 3.9281 & 1.49220 \\
\hline For medical reasons & 139 & 1.00 & 5.00 & 2.0000 & .97058 \\
\hline Valid N (listwise) & 139 & & & & \\
\hline
\end{tabular}


roles to increase their learning experience. In addition, it might help them to find a better job in the future. Some organizations today start to adopt a flexible working arrangement that permit a high level of flexibility in their attendance system and allowing a room for employees to have enough time outside the work. Employees might take this opportunity to improve their monthly income as well as professional life if they join any study program. There are also some important benefits provided by an effective absenteeism police include the decreasing of work-related accidents, decreasing the work-related illness as well as decreasing the work-related stress.
Table (2): Descriptive Statistics: Positive Effects of an Effective Absenteeism Policy

\begin{tabular}{lrrc}
\hline & N & Mean & $\begin{array}{c}\text { Std. } \\
\text { Deviation }\end{array}$ \\
\hline Creation of work -life balance & 139 & 1.9424 & .98371 \\
\hline Decreasing of work-related stress & 139 & 2.1942 & 1.16020 \\
\hline Ability to accomplish some personal activities and needs & 139 & 1.9353 & 1.00151 \\
\hline Decreasing of work-related illness & 139 & 2.4748 & 1.27023 \\
\hline Decreasing of work-related accidents & 139 & 2.7842 & 1.41300 \\
\hline A chance for entertainment and relaxation & 139 & 2.3381 & 1.43231 \\
\hline A chance for academic and professional development & 139 & 2.4892 & 1.42120 \\
\hline Increasing the level of attention during working days & 139 & 2.5252 & 1.37962 \\
\hline Help to energizing & 139 & 2.1727 & .95499 \\
\hline A chance to find a new better job & 139 & 3.0144 & 1.25678 \\
\hline A chance to increase the personnel income by doing & 139 & 2.6187 & .91995 \\
\hline another job & 139 & 3.0072 & 1.58570 \\
\hline Enable my colleagues who do my job to enrich their & 139 & 2.8561 & 1.31083 \\
\hline experiences & 139 & 2.1583 & .90297 \\
\hline Creation of work -life balance & 139 & 2.0072 & 1.03907 \\
\hline Decreasing of work-related stress & & & \\
\hline Ability to accomplish some personal activities and needs & 139 & & \\
\hline Valid N (listwise) & & &
\end{tabular}
An effective absenteeism policy might help organization to prevent from presenteeism behavior if the employees are feeling ill and decide to come to work because of ineffective absenteeism policy. This behavior might increase the probability of disease spread and work-related accidents. It might also affect the quality of work by allowing employees to increase their professional as well as academic life. Some organizations have formulated special leave for professional certificate examination and higher studies. This policy improves employees" competency and their commitment to their organizations, the quality of the work done by allowing employees to have a time for relax and rest might also improve. The table also shows that an effective absenteeism policy might provide a room to improve work-life balance feeling, help employees to energize and decrease the rate of mistakes and rejections tasks while doing their job.

\section{Pearson Correlation Coefficient Analysis ( $\mathrm{N}=60)$}

Table (3): The Relationship between Absenteeism Policy and Attendance Behavior Satisfaction

\begin{tabular}{|c|c|c|c|c|c|c|c|c|}
\hline \multicolumn{3}{|c|}{ Control Variables } & \multirow{2}{*}{$\frac{\mathrm{Q7}}{1.000}$} & \multirow{2}{*}{$\frac{\mathrm{Q10}}{.650}$} & \multirow{2}{*}{$\frac{\text { Q11 }}{.731}$} & \multirow{2}{*}{$\frac{\mathrm{Q} 13}{.750}$} & \multirow{2}{*}{$\begin{array}{l}\text { Q15 } \\
.696 \\
\end{array}$} & \multirow{2}{*}{$\frac{\mathrm{Q} 19}{.615}$} \\
\hline \multirow{18}{*}{$\begin{array}{c}\text { I Feel } \\
\text { Satisfy } \\
\text { on my } \\
\text { Monthly } \\
\text { Attendance }\end{array}$} & \multirow{3}{*}{$\begin{array}{l}\text { Our absenteeism policy helps me to } \\
\text { balance my life and my work. }\end{array}$} & Correlation & & & & & & \\
\hline & & Significance (2-tailed) & & .000 & .000 & .000 & .000 & .000 \\
\hline & & $\mathrm{df}$ & 0 & 136 & 136 & 136 & 136 & 136 \\
\hline & \multirow{3}{*}{$\begin{array}{l}\text { Few days absent decrease the work-relat- } \\
\text { ed illness. }\end{array}$} & Correlation & .650 & 1.000 & .796 & .774 & .663 & .546 \\
\hline & & Significance (2-tailed) & .000 &. & .000 & .000 & .000 & .000 \\
\hline & & $\mathrm{df}$ & 136 & 0 & 136 & 136 & 136 & 136 \\
\hline & \multirow{3}{*}{$\begin{array}{l}\text { Few days absent decrease the probability } \\
\text { of work-related accidence. }\end{array}$} & Correlation & .731 & .796 & 1.000 & .796 & .870 & .556 \\
\hline & & Significance (2-tailed) & .000 & .000 &. & .000 & .000 & .000 \\
\hline & & $\mathrm{df}$ & 136 & 136 & 0 & 136 & 136 & 136 \\
\hline & \multirow{3}{*}{$\begin{array}{c}\text { Few days absent help me to improve } \\
\text { professional and academic life. }\end{array}$} & Correlation & .750 & .774 & .796 & 1.000 & .850 & .719 \\
\hline & & Significance (2-tailed) & .000 & .000 & .000 &. & .000 & .000 \\
\hline & & $\mathrm{df}$ & 136 & 136 & 136 & 0 & 136 & 136 \\
\hline & \multirow{3}{*}{$\begin{array}{l}\text { Few days absent decrease the work-relat- } \\
\text { ed stress. }\end{array}$} & Correlation & .696 & .663 & .870 & .850 & 1.000 & .622 \\
\hline & & Significance (2-tailed) & .000 & .000 & .000 & .000 & & .000 \\
\hline & & $\mathrm{df}$ & 136 & 136 & 136 & 136 & 0 & 136 \\
\hline & \multirow{3}{*}{$\begin{array}{l}\text { The organization where I work has a } \\
\text { clear, understood and effective absentee- } \\
\text { ism policy. }\end{array}$} & Correlation & .615 & .546 & .556 & .719 & .622 & 1.000 \\
\hline & & Significance (2-tailed) & .000 & .000 & .000 & .000 & .000 & . \\
\hline & & $\mathrm{df}$ & 136 & 136 & 136 & 136 & 136 & 0 \\
\hline
\end{tabular}


As shown in table 3, the correlation matrix indicates that the independent variables positively correlated with the dependent variable. According to the results, the satisfaction level of monthly attendance recork might related to the attendance policy is positively related to different factors like the availability of life-balance arrangement, and the flexibility that provided by the existing attendance policy. Thus, hypotheses $\mathrm{H} 1$, $\mathrm{H} 2, \mathrm{H} 3, \mathrm{H} 4, \mathrm{H} 5$ and $\mathrm{H} 6$ supported according to the table 3.

\section{Conclusion \& Recommendations}

The majority of the researches on absence focused on the negative effects of absenteeism behavior from the employers' point of view. Very few studies try to explore the positive effects of absenteeism behavior on employees' life, safety, development and wellbeing. This study tries to explore the benefits and positive outcomes of being a way from work for some times. This study found a positive relationship between an effective absenteeism policy that used by organization to manage theirs people attendance behavior and the satisfaction of employees on their absence behavior. This study also found that an effective absenteeism policy might decrease the work-related stress. This finding is support CIPD (2019), SHRM (2018) findings on their annual surveys and (Abdullah \& Lee, 2012). This finding shows the proactive role that played by HR department specifically on their responsibilities toward the wellbeing programs that might help employee improve their absenteeism record. We can say that if employees have some days-off, this might help them to decrease the work-related stress. Some organizations today start to provide flexible working arrangements to solve this problem. This study also finds a positive relationship between an effective absenteeism policy and the work-life balance. If organizations track their employees' attendance well and create conducive working environment as well as using an effective absenteeism policy, this might improve the work-life balance and the overall attendance satisfaction for employees and the employers. This study also finds a positive correlation between an effective absenteeism policy and the work-related accidents. If the HRM policies allow having a chance of excuse or an off-days or any special leaves, these might decrease the probability of having an accidents while doing their jobs. The well-job design, autonomy, some freedom for making decisions might also improve the accidents records inside organization. This finding is also supported by the study of (Lu et al., 2014). Organizations might face a high level of level of work-related accidents if their absenteeism policy is not formulated effectively to meet the needs of stakeholders.

This study also finds a correlation between an effective absenteeism policy and the academic as well as professional development of employees. The HRM absenteeism policy must well formulated to give employees a chance to join a professional training program or to continue their higher studies. Today, some organizations provide their employees with special paid leave to sit to a professional exams or academic exams. These types of organizations believe that the cost of this leave is less than the benefits in the long-term.

The study also finds that if employers provide their employees days off through an effective absenteeism policy, this might decrease the probability of have a work-related illness. Some organizations nowadays start to provide their infectious employees additional leave days until them treated completely. This practice might safe others of not having the same illness like bird flu, general flu diseases etc.

Human resources management departments should pay attention for theirs current absenteeism policy and try to review it continually. We recommend for HRM to adopt evidence-based methods when deciding to make any change on their absenteeism policy and calculate the benefits and costs of each decisions. In addition, they should consider the benefits of employees as well as employers when modification decision made.

Another recommendation is for the future researches. We recommend focusing research papers on the factors that affect employees' behaviors and controlled by the employers. We can say that people are the most valuable asset in all organizations, they are not a cost center, and we should treat them always like this. 


\section{Contribution of this Study}

This study tries to focus on the positive side of absenteeism for both employees and employers. Past studies on absenteeism focused on its negative side and it always study the phenomena from the viewpoints of employers. Many studies try to explore the impact of absenteeism on the profits sharing, overall cost and other financial indicators as stated by (Peel \& Wilson, 1990). Today organizations live in a dynamic environment where legal, technological, and the other environmental factors are not stable and organizations should adapt to this change in order to survive. It recommended for all organizations to formulate an effective absenteeism policy that satisfy all stakeholders and evaluate regularly this policy. As mentioned by (Guest, 2011) senior HR managers are responsible of following up the implementation of policies and practice and should report if these policies and practices are effective or not. If people have been given a chance to be absent voluntary or involuntary through an effective absenteeism policy designed by specialized HRM managers, this might improve their job satisfaction and lead to decrease the total costs by improving the quality of work, increasing productivity as well as commitment towards their organization. We can also say that organizations today are intensively competing to improve their performance and satisfy all stakeholders. If these organizations have an effective absenteeism policy that permits employees to join a professional training programs or an advanced study, this also might help organizations to be more competitive because of its most valuable assets.

This study also a contribution when stated that an organizational well-being programs, health and safety programs as well as an effective absenteeism policy might lead to reduce the probability of sick leaves and its direct costs. In addition, these factors might improve the attendance behavior. And we can also agree with (MacGregor \& Cunningham, 2018) when mentioned that if organizations able to decrease the presenteeism as an unwilling behavior, it might decrease the employee's sick leaves and improving their well-being and health at work.

\section{Acknoweldgement}

We thank all those who contributed to this study and participate as a respondent, data collection and management. Special thanks for Mr. Mohammed AlSaffar and his team fellow.

\section{Disclosure Statement}

There is No potential conflict of interest reported by the authors. 


\section{REFERENCES}

Abdullah, D. N. M. A. \& Lee, O. Y. (2012). “Effects of wellness programs on job satisfaction, stress and absenteeism between two groups of employees (attended and not attended)", Procedia-Social and Behavioral Sciences, 65, pp. 479-484.

- Athanasou, J. \& Murphy, G. (1981). "Absenteeism and behaviour modification: A Review", Asia Pacific Journal of Human Resources, 19 (1), 10-14.

- Baker-McClearn, D.; Greasley, K.; Dale, J. \& Griffith, F. (2010). “Absence management and presenteeism: The pressures on employees to attend work and the impact of attendance on performance", Human Resource Management Journal, 20 (3), pp. 311-328.

- D'Agostino, E. M.; Day, S. E.; Konty, K. J.; Larkin, M.; Saha, S. \& Wyka, K. (2018). “Peer reviewed: individual-level fitness and absenteeism in New York city middle school youths, 2006-2013. Preventing chronic disease, 15.

- Dew, K.; Keefe, V. \& Small, K. (2005). "Choosing'to work when sick: workplace presenteeism", Social Science \& Medicine, 60 (10), pp. 2273-2282.

- Duncombe, D. C. (2019). “Factors influencing voluntary absenteeism among healthcare workers in the Bahamas", Nursing Economics, 37 (2), pp. 92-109.

- Edwards, P. \& Scullion, H. (1984). "Absenteeism and the control of work", The Sociological Review, $32(3)$, pp. 547-572.

- $\quad$ Fang, T.; Lee, B.; Timming, A. \& Fan, D. (2019). The effects of work-life benefits on employment outcomes in Canada: A multivariate analysis. Vol. 74, No. 2, Spring.

- Furnham, A. \& Bramwell, M. (2006). "Personality factors predict absenteeism in the workplace", Individual Differences Research, 4 (2).

- García Mainar, l.; Green, C. P. \& Navarro Paniagua, M. (2018). “The Effect of Permanent Employment on Absenteeism: Evidence from Labor Reform in Spain", ILR Review, 71 (2), pp. 525-549.

- $\quad$ Goff, S. J.; Mount, M. K. \& Jamison, R. L. (1990). “Employer supported child care, work/ family conflict, and absenteeism: A field study. Personnel Psychology, 43 (4), pp. 793-809.

- Guest, D. E. (2011). “Human resource management and performance: still searching for some answers", Human Resource Management Journal, 21 (1), pp. 3-13.

- Hemp, P. (2004). “Presenteeism: at work-but out of it", Harvard Business Review, 82 (10), pp. 49-58.

- $\quad$ Kim, J. S. \& Ryu, S. (2017). "Employee satisfaction with work-life balance policies and organizational commitment: A Philippine study", Public Administration and Development, 37 (4), PP. 260-276.

- $\quad$ Lu, M. L.; Nakata, A.; Park, J. B. \& Swanson, N. G. (2014). “Workplace psychosocial factors associated with work-related injury absence: A study from a nationally representative sample of Korean workers", International Journal of Behavioral Medicine, 21 (1), PP. 42-52.

- MacGregor, J. \& Cunningham, J. B. (2018). “To be or not to be... at work while ill: A choice between sickness presenteeism and sickness absenteeism in the workplace", Journal of Organizational Effectiveness: People and Performance, 5 (4), PP. 314-327.

- Matilla-Santander, N.; Lidón-Moyano, C.; González-Marrón, A.; Bunch, K.; Martín-Sánchez, J. C. \& Martínez-Sánchez, J. M. (2019). "Attitudes toward working conditions: are European Union workers satisfied with their working hours and work-life balance?", Gaceta Sanitaria, 33 , PP. 162-168. 
Mowday, R. T.; Porter, L. W. \& Steers, R. M. (2013). Employee-organization Linkages: The Psychology of Commitment, Absenteeism and Turnover. Academic press.

- $\quad$ Peel, M. J. \& Wilson, N. (1990). "Labour absenteeism: The impact of profit sharing, voice and participation", International Journal of Manpower, 11 (7), PP. 17-24.

- $\quad$ Steers, R. M. \& Rhodes, S. R. (1978). "Major influences on employee attendance: A process model", Journal of Applied Psychology, 63 (4), P. 391.

- Strömberg, C.; Aboagye, E.; Hagberg, J.; Bergström, G. \& Lohela-Karlsson, M. (2017). “Estimating the effect and economic impact of absenteeism, presenteeism, and work environment-related problems on reductions in productivity from a managerial perspective", Value in Health, 20 (8), PP. 1058-1064.

\section{- Onlines and Network Sources:}

- $\quad$ CIPD. (2019). Wellbeing Report. UK, pp.12-43, retrieved from: https://www.cipd.co.uk/knowledge/ culture/well-being/health-well-being-work

- $\quad$ CIPD. (2019). Absence management survey report. UK, pp.1-9, retrieved from:https://www. cipd.co.uk/knowledge/fundamentals/relations/absence/absence-management-surveys

- SHRM. (2014). Total financial impact of employee absence report. US, pp.1-3, retrieved from:https://www.shrm.org/hr-today/trends-and-forecasting/research-and- surveys/Documents/Total\%20Financial\%20Impact\%20of\%20Employee\%20Absences\%20Report.pdf

- SHRM. (2014). Employee absence survey, US, pp.1-3, retrieved from: https://www.shrm.org/ about-shrm/press-room/press releases/pages/employeeabsencessurvey.aspx 
